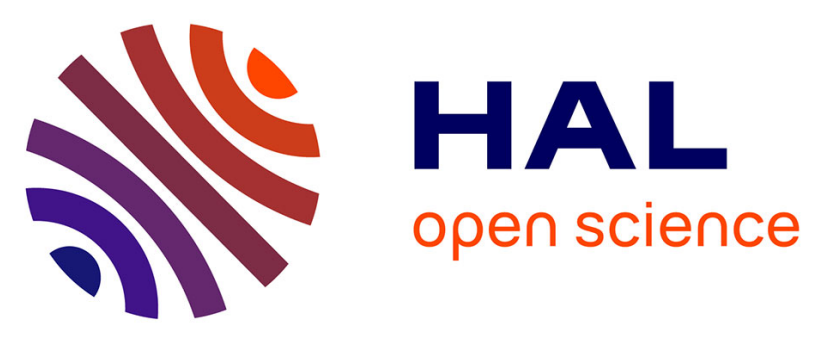

\title{
Contribution to the study of particle resuspension kinetics during thermal degradation of polymers
}

F. X. Ouf, S. Delcour, N. Azema, A. Coppalle, Laurent Ferry, F. Gensdarmes, J. M. Lopez-Cuesta, A. Niang, S. Pontreau, Jerôme Yon

\section{- To cite this version:}

F. X. Ouf, S. Delcour, N. Azema, A. Coppalle, Laurent Ferry, et al.. Contribution to the study of particle resuspension kinetics during thermal degradation of polymers. Journal of Hazardous Materials, 2013, 250-251, pp.298-307. 10.1016/j.jhazmat.2013.01.060 . hal-01613295

\section{HAL Id: hal-01613295 \\ https://hal.science/hal-01613295}

Submitted on 1 Jun 2021

HAL is a multi-disciplinary open access archive for the deposit and dissemination of scientific research documents, whether they are published or not. The documents may come from teaching and research institutions in France or abroad, or from public or private research centers.
L'archive ouverte pluridisciplinaire HAL, est destinée au dépôt et à la diffusion de documents scientifiques de niveau recherche, publiés ou non, émanant des établissements d'enseignement et de recherche français ou étrangers, des laboratoires publics ou privés.

\section{(1) (1) $\$$}

Distributed under a Creative Commons Attribution - NonCommercial - NoDerivatives| 4.0 


\title{
Contribution to the study of particle resuspension kinetics during thermal degradation of polymers
}

\author{
F.-X. Ouf a,*, S. Delcour ${ }^{\mathrm{a}, \mathrm{b}}$, N. Azema ${ }^{\mathrm{b}}$, A. Coppalle ${ }^{\mathrm{c}}$, L. Ferry ${ }^{\mathrm{b}}$, F. Gensdarmes ${ }^{\mathrm{a}}$, J.-M. Lopez-Cuesta ${ }^{\mathrm{b}}$, \\ A. Niang ${ }^{\mathrm{a}}, \mathrm{S}$. Pontreau ${ }^{\mathrm{a}}$, J. Yon ${ }^{\mathrm{c}}$
}

a Institut de Radioprotection et de Sûreté Nucléaire, Laboratoire de Physique et de Métrologie des Aérosols, B.P. 68, 91192 Gif-Sur-Yvette Cedex, France

${ }^{\mathrm{b}}$ Ecole des Mines d'Alès, Centre des Matériaux (CMGD)-Pôle Matériaux Polymères Avancés, 6 Avenue de Clavières, 30319 Alès Cedex, France

${ }^{\text {c } C N R S ~ U M R ~ 6614-C O R I A, ~ U n i v e r s i t e ́ ~ e t ~ I N S A ~ d e ~ R o u e n, ~ 76801, ~ B P-12, ~ S a n t ~ E t i e n n e ~ d u ~ R o u v r a y, ~ F r a n c e ~}$

\section{H I G H L I G H T S}

- We experiment the airborne release of particles during thermal degradation of polymers.

- A "peak of release" was identified during the first instances of thermal stress of Plexiglas.

- The duration of the peak of release was linked to the heat flux applied to the Plexiglas.

- Heat flux has a low influence on the airborne release fraction (ARF).

- The influence of the diameter of particles on the ARF depends on polymer.
G R A P H I C A L A B S T R A C T
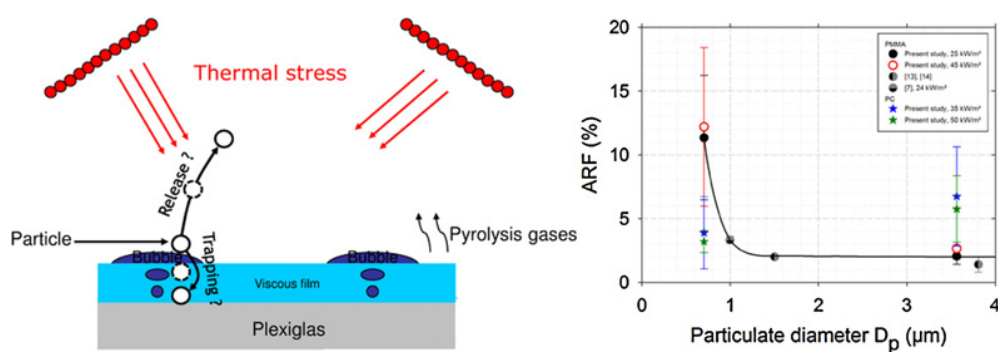

\section{A B S T R A C T}

Experimental results are reported on the resuspension of particles deposited on polymer samples representative of glove boxes used in the nuclear industry, under thermal degradation. A parametric study was carried out on the effects of heat flux, air flow rate, fuel type and particle size distribution. Small-scale experiments were conducted on $10 \mathrm{~cm} \times 10 \mathrm{~cm}$ PolyMethyl MethAcrylate (PMMA) and PolyCarbonate (PC) samples covered with aluminium oxide particles with physical geometric diameters of 0.7 and $3.6 \mu \mathrm{m}$. It was observed for both polymer (fuel) samples that heat flux has no effect on the airborne release fraction (ARF), whereas particle size is a significant parameter. In the case of the PMMA sample, ARF values for 0.7 and $3.6 \mu \mathrm{m}$ diameter particles range from $12.2 \%( \pm 6.2 \%)$ to $2.1 \%( \pm 0.6 \%)$, respectively, whereas the respective values for the PC sample range from $3.2 \%( \pm 0.8 \%)$ to $6.9 \%( \pm 3.9 \%)$. As the particle diameter increases, a significant decrease in particle release is observed for the PMMA sample, whereas an increase is observed for the PC sample. Furthermore, a peak airborne release rate is observed during the first instants of PMMA exposure to thermal stress. An empirical relationship has been proposed between the duration of this peak release and the external heat flux.

Keywords:

Airborne release fraction

Fire

PMMA

PC

Aluminium oxide

\footnotetext{
* Corresponding author. Tel.: +33 1690860 73; fax: +3316019 3061 E-mail address: francois-xavier.ouf@irsn.fr (F.-X. Ouf).
}

\section{Introduction}

In the nuclear industry, radioactive products are manufactured, handled and treated in a confined manner using special glove boxes mainly composed of polymethyl methacrylate (PMMA) or polycarbonate (PC) sheets. The handling of radioactive materials in powder form may 


\section{List of symbols}

$\mathrm{Al}_{2} \mathrm{O}_{3} \quad$ aluminium oxide or alumina

ARF airborne release fraction (\%)

ARR airborne release rate $\left(\mathrm{h}^{-1}\right)$

$D_{\mathrm{ae}} \quad$ aerodynamic diameter of particle considered $(\mu \mathrm{m})$

$D_{\mathrm{p}} \quad$ geometric diameter of particle considered $(\mu \mathrm{m})$

$\mathrm{d} t$ time interval considered for computation of parameters $(s)$

$\mathrm{DT}_{\text {fire }}$ duration of fire $(\mathrm{s})$

$\mathrm{DT}_{\text {peak }}$ duration of peak release (s)

ICP-MS inductively coupled plasma-mass spectrometry

$m_{\text {Aer Rel }}$ aerosol mass released during time interval considered (mg)

$m_{\text {Aer Init }}$ initial aerosol mass deposited on polymer sample (mg)

$\dot{m}_{\text {fuel }} \quad$ fuel mass loss rate per second and per surface area $\left(\mathrm{g} / \mathrm{m}^{2} \mathrm{~s}\right)$

$m_{\text {fuel } t} \quad$ fuel mass at time $t(\mathrm{~g})$

$m_{\text {Tot Aer Rel }}$ total aerosol mass released (mg)

MMAD mass median aerodynamic diameter $(\mu \mathrm{m})$

MTU110 alumina powder with $\mathrm{MMAD}=1.4 \mu \mathrm{m}$ and $D_{\mathrm{p}}=0.7 \mu \mathrm{m}$

PC polycarbonate

PMMA polymethyl methacrylate

$\mathrm{s}$ second

$t \quad$ time interval considered (s)

$T_{\text {peak }} \quad$ time delay of peak release (s)

SPM102 alumina powder with $\mathrm{MMAD}=7.1 \mu \mathrm{m}$ and $D_{\mathrm{p}}=3.6 \mu \mathrm{m}$.

contaminate the inner walls of glove boxes and this particulate surface contamination may be released in the event of an accident such as a fire [1]. This release of radioactive particles is of great interest in the field of nuclear safety since the particle size distribution covers the range of inhalable and lung deposition fractions [2,3]. Beyond the nuclear industry, the role of nanomaterials in our society has grown significantly over the past decade and the issue of aerosol release during combustion of nanocomposites has become a matter of increasing concern in industrial applications [4,5]. Therefore, in order to quantify the toxicological and environmental impact of a fire occurring in an industrial or nuclear facility, it is necessary to be able to predict the release rate of contaminant aerosols under such accident conditions. Since a fire is an extremely complex event leading to various physical phenomena, no research is currently available describing such conditions in a phenomenological manner. Nevertheless, regarding airborne releases in the event of a polymer fire, several experimental studies are reported in the literature addressing different scales (i.e. from the analytical scale [6-12] to the real scale $[13,14]$ ), contaminants (oxide and salt) and fire conditions (flaming, non-flaming). Similarly to the results reported by previous authors [15], we present in Fig. 1 a summary of available data on airborne release fractions (ARF: mass of contaminant released in aerosol form divided by the overall mass of contaminant deposited) for the glove box materials most commonly used in the nuclear industry (mainly Plexiglas ${ }^{\mathrm{TM}}$ PMMA and LEXAN ${ }^{\mathrm{TM}} \mathrm{PC}$ ) and for main contaminant particles $\left(\mathrm{UO}_{2}\right.$ [6,7]; $80 \% \mathrm{UO}_{2}-20 \% \mathrm{PuO}_{2}$ [8,9]; $\mathrm{CeO}_{2}$ [10,12,14]; $84 \% \mathrm{CeO}_{2}-16 \% \mathrm{EuO}_{2}$ [13,14]; $\mathrm{CsCl}[14]$; $\mathrm{Co}_{2} \mathrm{O}_{3}$ [14]; $\mathrm{La}_{2} \mathrm{O}_{3}$ [14]). It is clearly apparent that a significant discrepancy could be identified between the results obtained from different experimental studies. In many cases, the discrepancies observed for one particular fuel could be associated with different experimental conditions and/or procedures. No specific parametric

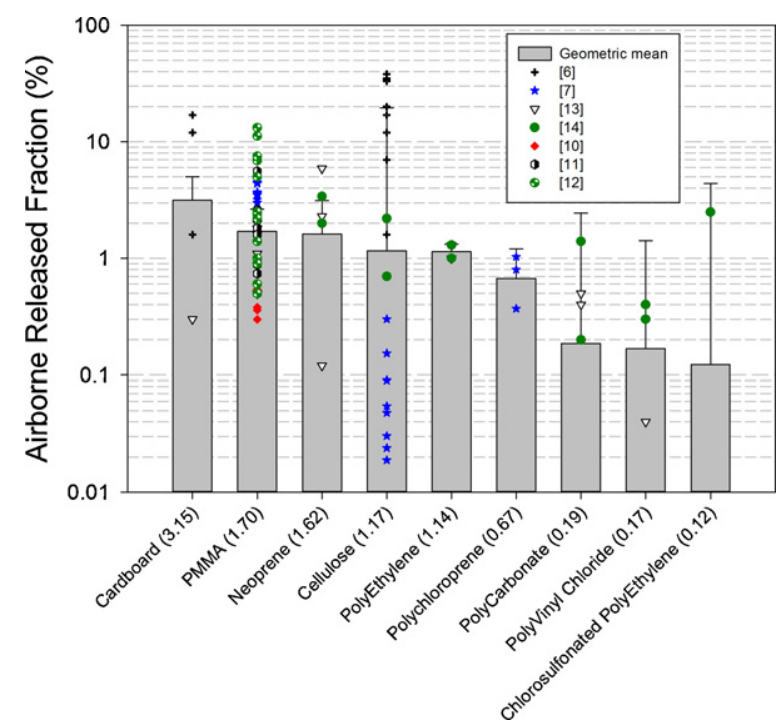

Fig. 1. Airborne release fraction for powders deposited on different solid fuels (dots represent experimental results while geometric mean values, given in brackets, are represented by each bar of the histogram).

study has been conducted addressing the effects of heat flux or physical diameter of contaminant particles.

Beyond these discrepancies, an analysis of the literature raises the issue of the relevance of such experiments conducted under different conditions (heat flux, vertical or horizontal orientation) and with different particulates (aluminium, caesium, europium, uranium oxides, etc.). In most cases, the aerodynamic particle diameter $\left(D_{\mathrm{ae}}\right)$ has been considered because it is a size parameter that can be easily determined experimentally (particularly by means of a cascade impactor [12,13]). Nevertheless, it should be kept in mind that the aerodynamic diameter represents the diameter of a sphere with the same settling velocity as the particles considered and a density of $1000 \mathrm{~kg} / \mathrm{m}^{3}$. Such a diameter is useful for characterizing the size distribution of an aerosol but needs to be converted to a geometric diameter (taking into account particle density and shape factor) in order to describe the behaviour of a particle deposited on a stable surface and to compute the forces applied to this particle (adhesion, drag, lift, etc.). For example, recent theoretical developments $[16,17]$ have demonstrated that the most relevant size parameter for modelling air flow resuspension is the physical particle diameter (geometric diameter for a sphere) rather than the aerodynamic diameter. Such an approach is suitable for nearly spherical particles whose geometric diameter could be easily defined, but transposition to irregularly shaped or agglomerated particles (fibres, metal oxides, combustion aerosols, etc.) is not a trivial issue and requires further theoretical development.

Despite this issue, some useful conclusions may be drawn from the available literature on polymer samples. Indeed, the results obtained by several authors $[7,13]$ reveal that the sample type (i.e. polymer composition) has an impact on the quantity of aerosol released. According to several authors, the bubbles produced during pyrolysis of PMMA samples (mainly MMA) significantly increase particle release and are one of the explanations for the peak release phenomenon first observed in the 1980s [8,9,13]. Nevertheless, this peak release phenomenon has not been described in a quantitative manner and, considering the scattering of experimental results available in the literature, the effects of heat flux and particle diameter have been scarcely investigated. Consequently, the aim of the present work is to provide, for a given particulate material, more experimental evidence on the significant parameters involved (sample type, heat flux, particle size distribution) 


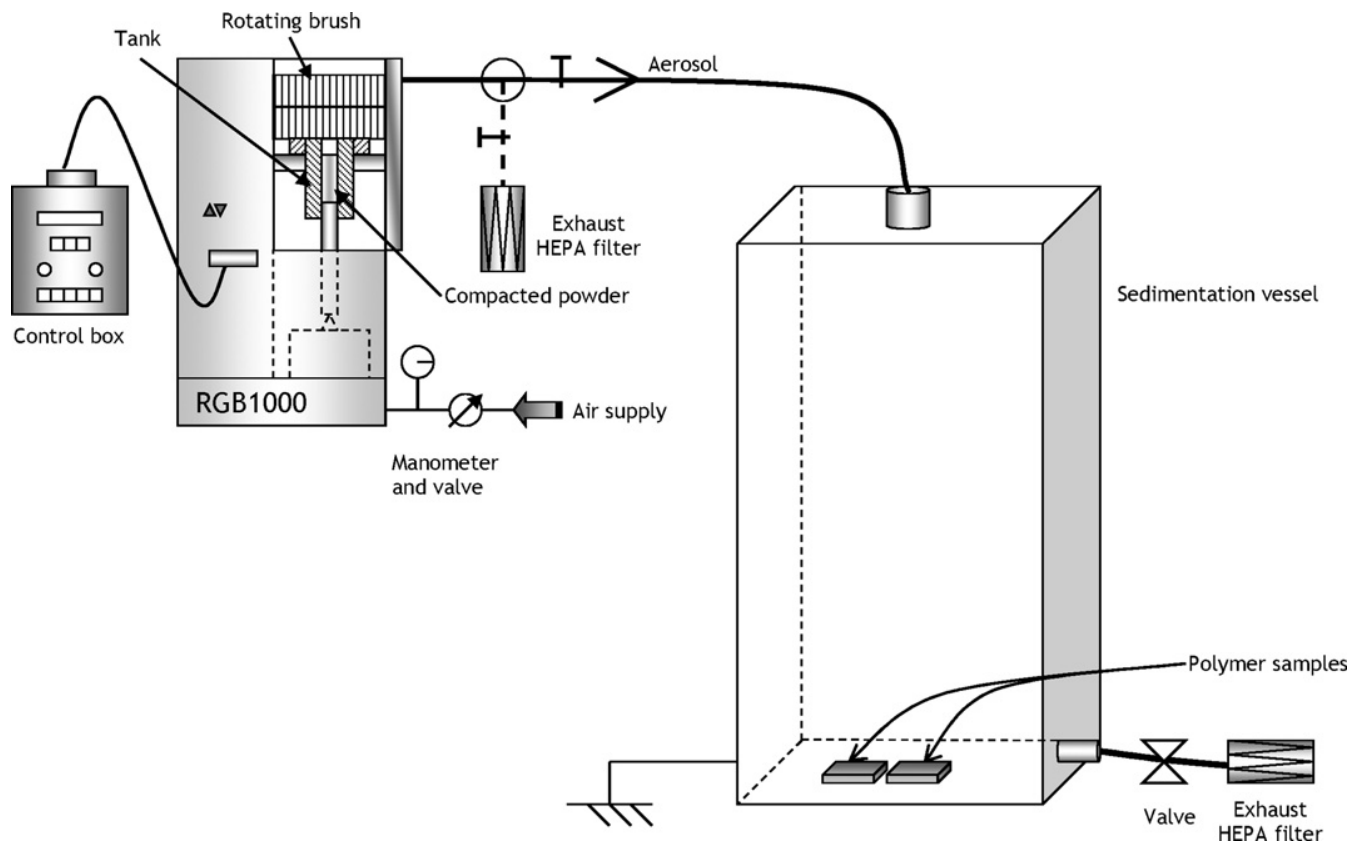

Fig. 2. Experimental set up for particle deposition on polymer samples.

and on the time-based evolution of airborne release during thermal degradation of different polymer samples.

\section{Experimental procedure}

\subsection{Aerosol contamination and choice of materials}

Aluminium oxide (alumina, $\mathrm{Al}_{2} \mathrm{O}_{3}$, Alumines Durmax S.A.) was chosen as a particulate material because it is commercially available with different size distributions and because it is a very stable material that is hardly oxidized under the thermodynamic conditions of a fire. Two thermoplastic polymers used in the composition of glove boxes were investigated: polymethyl methacrylate (PMMA, PMMA 1.18, Delire SA), and polycarbonate bisphenol-A (PC, LEXAN ${ }^{\mathrm{TM}}$ 9030-112, General Electric). The main difference between these polymers is that during thermal degradation, PMMA depolymerises at more than 99\% [18] whereas intensive and intumescent charring is observed for PC [19]. Polymer sample sizes were $100 \mathrm{~mm} \times 100 \mathrm{~mm} \times 8 \mathrm{~mm}$ and $100 \mathrm{~mm} \times 100 \mathrm{~mm} \times 9.5 \mathrm{~mm}$ for PMMA and PC, respectively. Polymer samples were covered with $\mathrm{Al}_{2} \mathrm{O}_{3}$ particles according to a specific protocol (see Fig. 2). Alumina powders were dispersed in a sedimentation chamber $(99 \mathrm{~cm} \times 30 \mathrm{~cm} \times 15 \mathrm{~cm})$ for 5 min using a rotating brush generator (RBG 1000 PALAS $^{\odot}$, powder feed rate: $130 \mathrm{~mm} / \mathrm{h}$, rotating brush speed: $1160 \mathrm{rpm}$, air pressure: 2 bar corresponding to $80 \mathrm{~L} / \mathrm{min}$ ). Dispersion was then stopped and the chamber, filled with alumina, was hermetically sealed. Alumina particles were deposited by sedimentation on polymer samples placed at the bottom of the chamber, so as to obtain a uniform surface deposition of $1 \mathrm{mg} / \mathrm{cm}^{2}$. The spatial homogeneity of the deposition was investigated by weighing 9 fibreglass filters $(25 \mathrm{~mm}$ in diameter) placed on the polymer sample during particle sedimentation inside the chamber. Discrepancies ranging from $-5 \%$ to $+12 \%$ were reported between the particle deposition mass per area measured on these filters and the expected homogeneous contamination deposition of $1 \mathrm{mg} / \mathrm{cm}^{2}$. Moreover, the mass of the particles deposited was monitored by adjusting the generation parameters and by weighing the polymer samples before and after contamination.
Two different particle sizes were considered: a first powder (MTU110) having a mass median aerodynamic diameter (MMAD) of nearly $1.4 \mu \mathrm{m}$ and a second powder (SPM102) with a MMAD of $7.1 \mu \mathrm{m}$. It should be noted that these MMADs were measured with an ANDERSEN cascade impactor. The resulting particle size distributions are presented in Fig. 3. Nevertheless, even though the MMAD is extremely useful from an experimental point of view, one must keep in mind that it represents the diameter of a spherical particle with the same settling velocity as the particle considered. By definition, the aerodynamic diameter cannot be used to describe the behaviour of a particle deposited on the surface of a polymer. The analysis of experimental results will therefore be based on the geometric particle diameter $D_{\mathrm{p}}$. Assuming a density $\left(\rho_{\mathrm{p}}\right)$ of $3980 \mathrm{~kg} / \mathrm{m}^{3}$ for alumina (in agreement with experimental measurements as per NF EN ISO 787-23) and spherically shaped particles (which is not entirely the case, see Fig. 3), the geometric diameter $D_{\mathrm{p}}$ can be computed using the equation $D_{\mathrm{p}} \propto$ $D_{\mathrm{ae}} / \sqrt{\rho_{\mathrm{p}}}$, yielding $0.7 \mu \mathrm{m}$ and $3.6 \mu \mathrm{m}$ for MTU110 and SPM102, respectively.

\subsection{Combustion test bench}

The combustion test bench is shown in Fig. 4. It consists of a FTT (fire testing technology) mass loss cone calorimeter modified for aerosol sampling. A conical radiant heater is used to apply heat fluxes ranging from 10 to $100 \mathrm{~kW} / \mathrm{m}^{2}$ on the surface of a horizontally oriented sample placed on a weighing cell. The distance between the heater and the sample is 25 and $60 \mathrm{~mm}$ for PMMA and PC, respectively. A $100 \mathrm{~mm}$ diameter exhaust duct is mounted above the radiant heater. The air flow rate (ranging from 50 to $150 \mathrm{~m}^{3} / \mathrm{h}$ ) is imposed by means of a fan and is monitored via a calibrated orifice linked to differential pressure transducers. Soot and contaminant particles are sampled via isokinetic probes, with the sampling flow rate maintained at $10 \mathrm{lpm}$ (litres per minute) with a Brooks mass flow controller. Special attention has also been given to the position of the sampling point on the exhaust duct so as to maintain a homogeneous particle concentration. The probe is located at a distance of $3.2 \mathrm{~m}$ from the radiant heater, and $0.8 \mathrm{~m}$ ( 8 diameters) after a $90^{\circ}$ bend, thus ensuring good mixing conditions at the sampling point as per ISO 2889/2010 and ANSI N13.1-1969. 


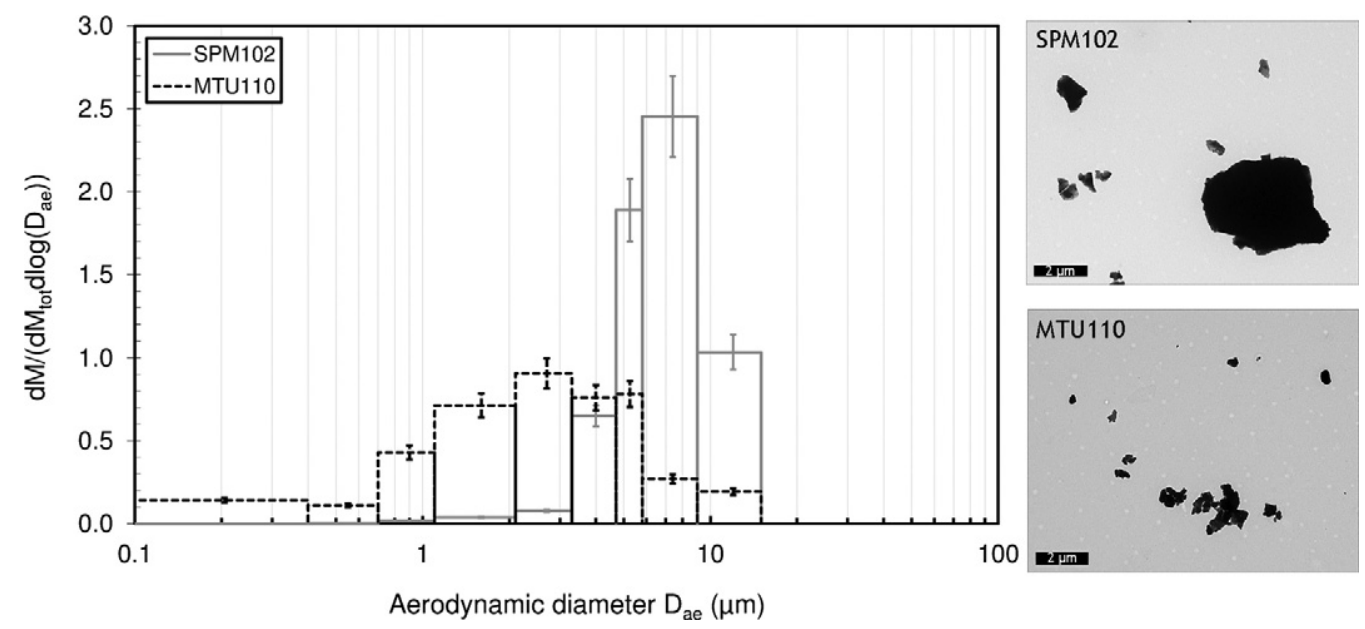

Fig. 3. Mass size distributions in terms of aerodynamic diameter and TEM micrographs of alumina powders.

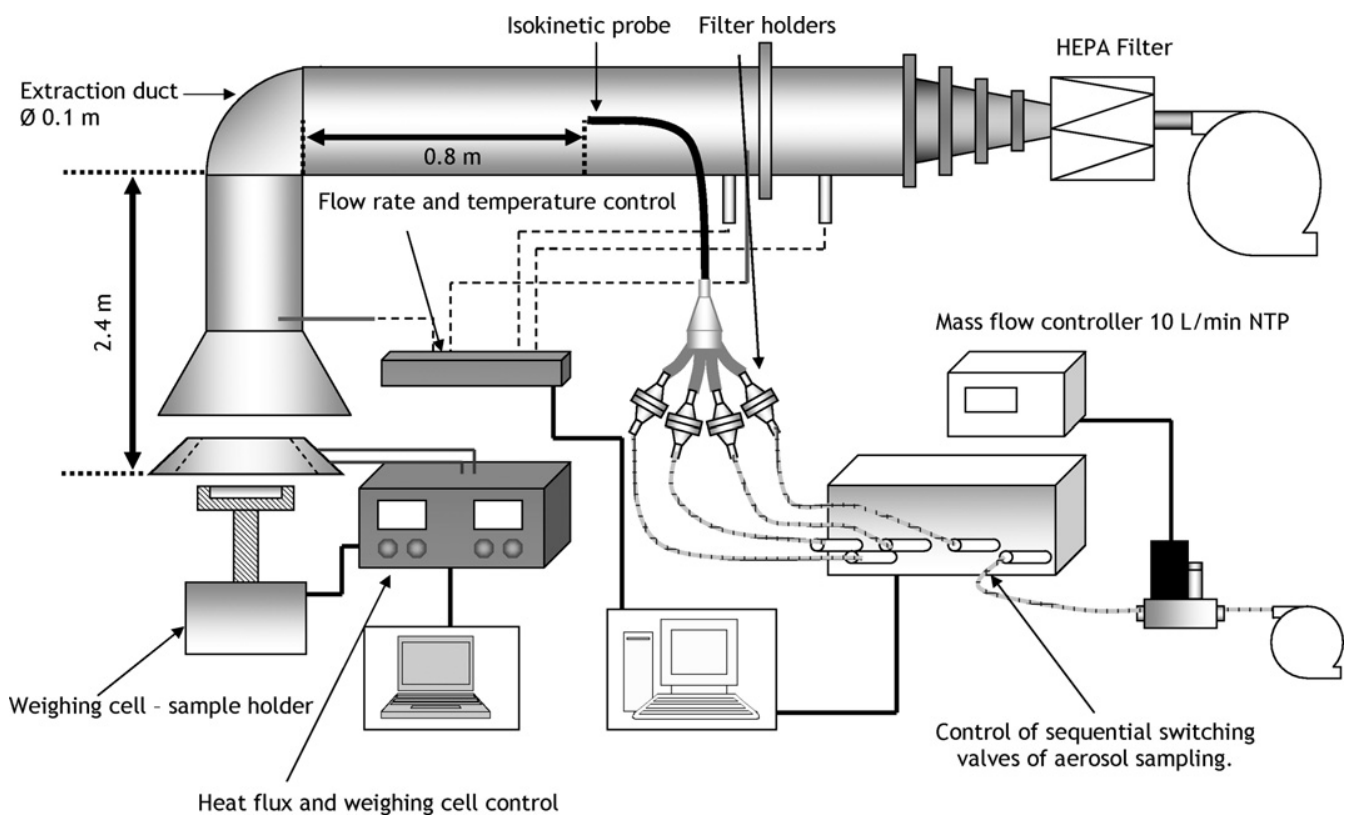

Fig. 4. Experimental device used for the thermal degradation of samples and aerosol measurement tools.

Four filters were sampled during each test and analyzed by ICP-MS (Inductively Coupled Plasma Mass Spectrometry) to measure their aluminium content. Two heat fluxes and two air flow rates were used to simulate non-flaming and flaming thermal degradation of polymer samples. Experimental conditions and theoretical particle losses (see Section 2.2) are presented in Tables 1 and 2.

\section{Analysis of samples}

\subsection{Experimental protocol}

The experimental resuspension protocol comprises several steps. Polymer samples with particle deposition are placed in the

Table 1

Experimental parameters considered for thermal degradation of PMMA.

PMMA samples $100 \mathrm{~mm} \times 100 \mathrm{~mm} \times 8 \mathrm{~mm}$ at $2.5 \mathrm{~cm}$ from the radiant panel, $100 \mathrm{mg}$ of alumina

Non-flaming conditions

\begin{tabular}{|c|c|c|c|c|}
\hline Experiment no. & Air flow rate $\left(\mathrm{m}^{3} / \mathrm{h}\right)$ & Heat flux $\left(\mathrm{kW} / \mathrm{m}^{2}\right)$ & $D_{\mathrm{p}}$ of alumina $(\mu \mathrm{m})$ & Theoretical losses (\%) \\
\hline $1-3$ & 50 & 25 & 3.6 & 64 \\
\hline $4-6$ & 50 & 25 & 0.7 & 19 \\
\hline $7-9$ & 100 & 25 & 3.6 & 16 \\
\hline $10-12$ & 100 & 25 & 0.7 & 16 \\
\hline \multicolumn{5}{|c|}{ Flaming conditions } \\
\hline Experiment no. & Air flow rate $\left(\mathrm{m}^{3} / \mathrm{h}\right)$ & Heat flux $\left(\mathrm{kW} / \mathrm{m}^{2}\right)$ & $D_{\mathrm{p}}$ of alumina $(\mu \mathrm{m})$ & Theoretical losses (\%) \\
\hline $13-15$ & 50 & 45 & 3.6 & 61 \\
\hline $16-18$ & 50 & 45 & 0.7 & 12 \\
\hline $19-21$ & 100 & 45 & 3.6 & 9 \\
\hline $22-24$ & 100 & 45 & 0.7 & 9 \\
\hline
\end{tabular}


Table 2

Experimental parameters considered for thermal degradation of PC.

\begin{tabular}{|c|c|c|c|c|}
\hline \multicolumn{5}{|c|}{$\begin{array}{l}\text { PC samples } 100 \mathrm{~mm} \times 100 \mathrm{~mm} \times 9.5 \mathrm{~mm} \text { at } 6 \mathrm{~cm} \text { from the radiant panel, } 100 \mathrm{mg} \text { of alumina } \\
\text { Non-flaming conditions }\end{array}$} \\
\hline Experiment no. & Air flow rate $\left(\mathrm{m}^{3} / \mathrm{h}\right)$ & Heat flux $\left(\mathrm{kW} / \mathrm{m}^{2}\right)$ & $D_{\mathrm{p}}$ of alumina $(\mu \mathrm{m})$ & Theoretical losses (\%) \\
\hline $1-3$ & 50 & 35 & 3.6 & 26 \\
\hline $4-6$ & 50 & 35 & 0.7 & 15 \\
\hline $7-9$ & 100 & 35 & 3.6 & 33 \\
\hline $10-12$ & 100 & 35 & 0.7 & 16 \\
\hline \multicolumn{5}{|c|}{ Flaming conditions } \\
\hline Experiment no. & Air flow rate $\left(\mathrm{m}^{3} / \mathrm{h}\right)$ & Heat flux $\left(\mathrm{kW} / \mathrm{m}^{2}\right)$ & $D_{\mathrm{p}}$ of alumina $(\mu \mathrm{m})$ & Theoretical losses (\%) \\
\hline $13-15$ & 50 & 50 & 3.6 & 31 \\
\hline $16-18$ & 50 & 50 & 0.7 & 16 \\
\hline $19-21$ & 100 & 50 & 3.6 & 34 \\
\hline $22-24$ & 100 & 50 & 0.7 & 19 \\
\hline
\end{tabular}

combustion chamber and the test begins with the application of heat flux $\left(t_{0}\right)$. Aerosols are sequentially sampled from aerosol filters during non-flaming and flaming tests. The polymer sample residue is then weighed and aerosol filters are analyzed by ICP-MS after each test. Tests are recorded with a High-Definition (HD) camera and the ignition time, delay of occurrence and duration of the peak release (significant particle release during the first instants of the experiment) are visually determined from the timecode of the HD video.

\subsection{Analysis of samples}

Since the airborne release fraction (ARF, see Section 2.3) is determined by filter sampling and ICP-MS, the chemical analysis of the samples was carefully carried out. Reference solutions and filters containing a known amount of alumina were prepared and analyzed according to the experimental protocol used for each sample. A linear relationship with a slope of 1.08 (within the measurement uncertainty range of the ICP-MS system) was obtained between reference and measured concentrations, thereby confirming the reliability of the method used to measure the aluminium mass on the samples. On the other hand, the loss of particles inside the exhaust duct was computed based on empirical relationships [20]. Since dilution within the hood is sufficient to bring the temperature inside the exhaust duct close to room temperature, thermophoresis was neglected and only diffusion, inertial impaction, sedimentation and turbulent diffusion were taken into consideration. According to these relationships and the thermophoresis hypothesis, the particle losses presented in Tables 1 and 2 depend on experimental conditions and are potentially underestimated. Furthermore, since the main assumption for estimating particle losses in our experimental test bench concerns the release during combustion of pure alumina particles without polymer or pyrolysis by-product coatings, it is difficult to evaluate the under or over-estimation of particle losses. To address this issue, the size distribution of airborne particles will be characterized by means of a cascade impactor.

\subsection{Measured and calculated parameters}

Several parameters were determined during the experiments conducted on the test bench. The first set of parameters concerns the thermal behaviour of the polymer samples during thermal degradation. The ignition time $T_{\text {ignition }}$ (delay between application of heat flux and self-ignition of fuel) and mass loss rate per surface area (fuel mass burned per second and per surface area $S_{\text {fuel }}$ ) were computed based on the data recorded by the weighing machine used in the test bench.

$\dot{m}_{\text {fuel }}=\frac{m_{\text {fuel } t}-m_{\text {fuel } t+d t}}{\mathrm{~d} t \cdot S_{\text {fuel }}}$, where $\dot{m}_{\text {fuel }}$, fuel mass loss rate per second and per surface area $\left(\mathrm{g} / \mathrm{m}^{2} \mathrm{~s}\right), m_{\text {fuel }} t$ and $m_{\text {fuel } t+\mathrm{d} t}$, fuel mass at time $t$ and $t+\mathrm{d} t(\mathrm{~g})$, $\mathrm{d} t$, time interval considered for computation of mass loss rate per surface area (s), $S_{\text {fuel }}$, fuel surface area $\left(\mathrm{m}^{2}\right)$.

Parameters associated with aerosol release were also measured or computed during each test. According to previous authors [9,12], aerosol releases during thermal degradation of PMMA samples are characterized by significant airborne releases during the first instants of the test, particularly prior to fuel ignition. Therefore, each test was recorded with a HD camera and the resulting videos were analyzed to visually determine the delay of occurrence $T_{\text {peak }}$ and duration $\mathrm{DT}_{\text {peak }}$ of this peak release. Sampling filters were used to compute the characteristic parameters of aerosol release kinetics. The first of these parameters is the airborne release rate (ARR), which is defined as the ratio between the released aerosol mass divided by the time interval considered (mainly the filter sampling time, ranging from 30 to $90 \mathrm{~s}$ ) and the initial aerosol mass deposited on the sample surface. The second parameter is the airborne release fraction (ARF), which is defined as the ratio between the total aerosol mass released during the test divided by the initial mass of particles deposited.

$\mathrm{ARR}=\frac{m_{\text {Aer Rel }}}{m_{\text {Aer Init }} \cdot \mathrm{d} t} \quad \mathrm{ARF}=\frac{m_{\text {Tot Aer Rel }}}{m_{\text {Aer Init }}}$,

where $m_{\text {Aer Rel }}$, aerosol mass released during time interval considered (mg), $m_{\text {Aer Init }}$, initial aerosol mass deposited on polymer sample (mg), $d t$, time interval considered for ARR ( $s$ ), $m_{\text {Tot Aer Rel }}$, total aerosol mass released (mg).

\section{Experimental results}

\subsection{Combustion parameters}

Table 3 presents parameters describing the thermal behaviour of the polymers considered. It should be noted that in the present study, contrary to previous studies on the thermal behaviour of such fuels [21], the fire is triggered without external energy (i.e. without a spark as in the case of a cone calorimeter). Consequently, the ignition time measured in the present study could be higher than that reported by previous authors for similar fuels via the international standard test method based on the use of a cone calorimeter [22-24]. Moreover, since thermal behaviour results are not influenced by the air flow rate, mean values are given hereafter for all tests conducted at 50 and $100 \mathrm{~m}^{3} / \mathrm{h}$ under non-flaming and flaming conditions. According to the results shown in Table 3 for the two alumina powders considered here $\left(D_{\mathrm{p}}=0.7\right.$ and $\left.3.6 \mu \mathrm{m}\right)$, the burning behaviour (mass loss rate and ignition time) of the fuel is not significantly modified by the alumina deposit. Nevertheless, a significant release of alumina was observed for PMMA 
Table 3

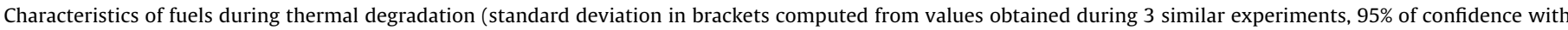
$k=2$ ).

\begin{tabular}{|c|c|c|c|c|c|c|}
\hline Fuel & Contaminant & Heat flux $\left(\mathrm{kW} / \mathrm{m}^{2}\right)$ & Mass loss rate $\left(\mathrm{g} / \mathrm{m}^{2} \mathrm{~s}\right)$ & Ignition time $(\mathrm{s})$ & Time delay of peak release $(\mathrm{s})$ & Duration of peak release $(\mathrm{s})$ \\
\hline \multirow[t]{4}{*}{ PMMA } & SPM102 & 25 & $7.5(2.4)$ & No ignition & $83(5)$ & $100(6)$ \\
\hline & & 45 & $29.5(4.7)$ & $140(88)$ & $34(6)$ & $34(9)$ \\
\hline & MTU110 & 25 & $8.5(1.7)$ & No ignition & $63(8)$ & $100(11)$ \\
\hline & & 45 & $30.2(2.3)$ & $141(95)$ & $20(3)$ & $37(7)$ \\
\hline \multirow[t]{4}{*}{ PC } & SPM102 & 35 & $1.2(0.6)$ & No ignition & N.V.I. & N.V.I. \\
\hline & & 50 & $10.5(2.8)$ & $182(76)$ & N.V.I. & N.V.I. \\
\hline & MTU110 & 35 & $2.0(1.6)$ & No ignition & N.V.I. & N.V.I. \\
\hline & & 50 & $11.0(3.0)$ & $153(82)$ & N.V.I. & N.V.I. \\
\hline
\end{tabular}

N.V.I., not visually identified.

during the first instants of the experiment, and the time delay of this peak depends on the size of the deposition particles. It must be noted that the results presented here concern only two contaminant particle diameters and that further investigation is needed to confirm this first conclusion, especially for fine $(0.1-1 \mu \mathrm{m})$ and coarse $(>10 \mu \mathrm{m})$ particles. In addition to this peak, one of the main differences observed between the two polymers is the type and volume of residues generated (see Fig. 5). For PMMA, the remaining mass is highly negligible, whereas the intumescing behaviour of PC tends to produce large amounts of residues.

\subsection{Particle resuspension kinetics}

For PMMA, regardless of size distribution and heat flux, a high release rate was observed during the first instants of the experiments and prior to ignition (see Fig. 6). This phenomenon has already been observed in the past [7-9,12] and is mainly due to bubbles formed during depolymerisation of PMMA [8]. The time delay and duration of this peak release phenomenon were determined using a high-definition camera and are presented in Table 3. The delay of occurrence is
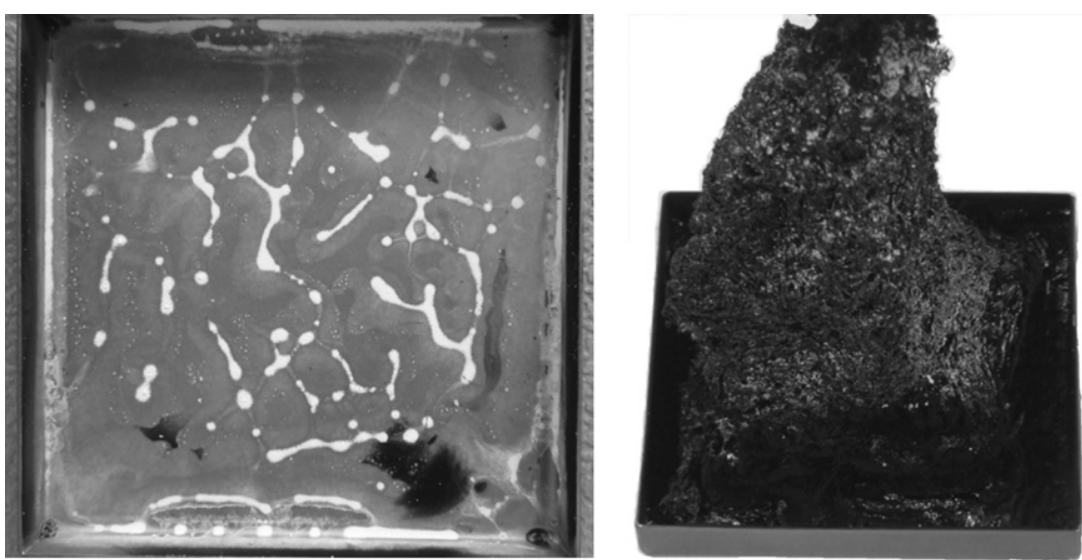

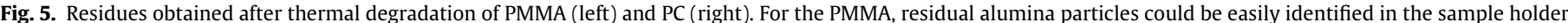
(white powder) while the intumescence of the PC involves a significant residue with some visible traces of alumina powder.

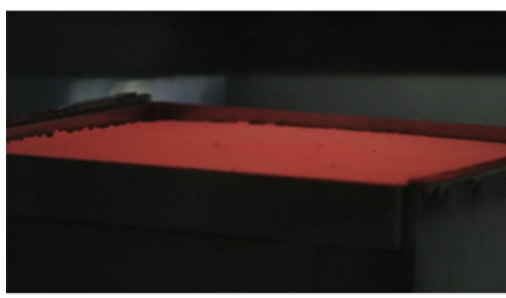

PMMA / MTU 110 - before «flash»

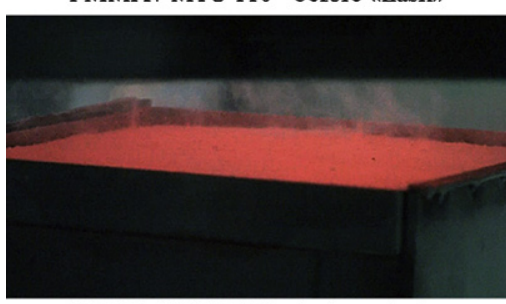

PMMA / MTU 110 - during «flash»

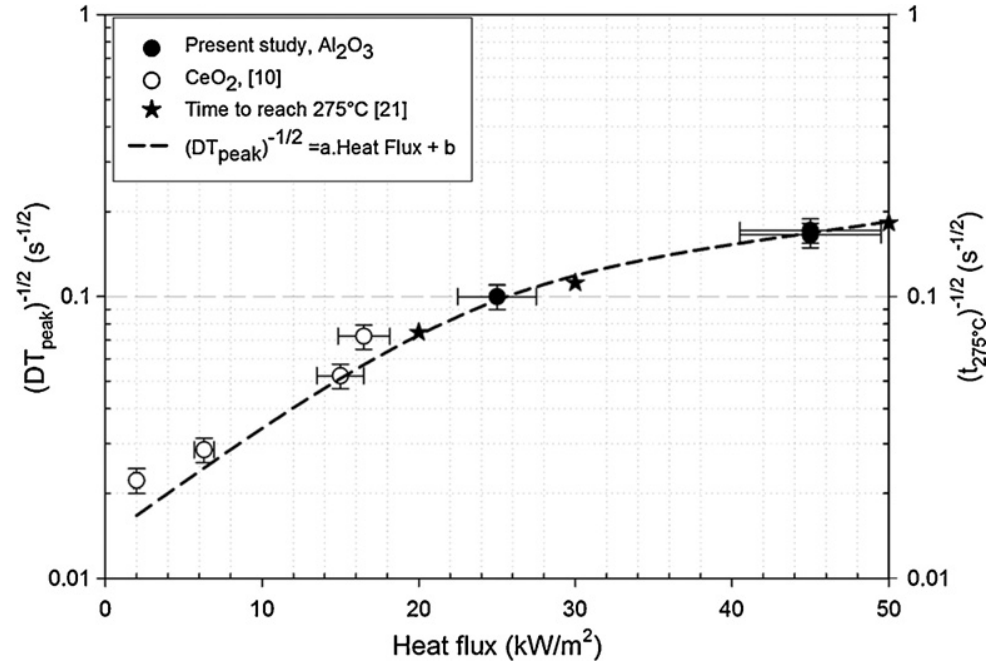

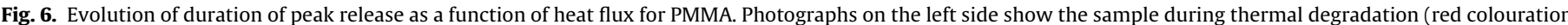

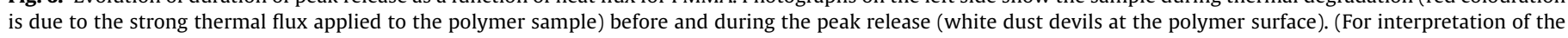
references to color in this figure legend, the reader is referred to the web version of this article.) 

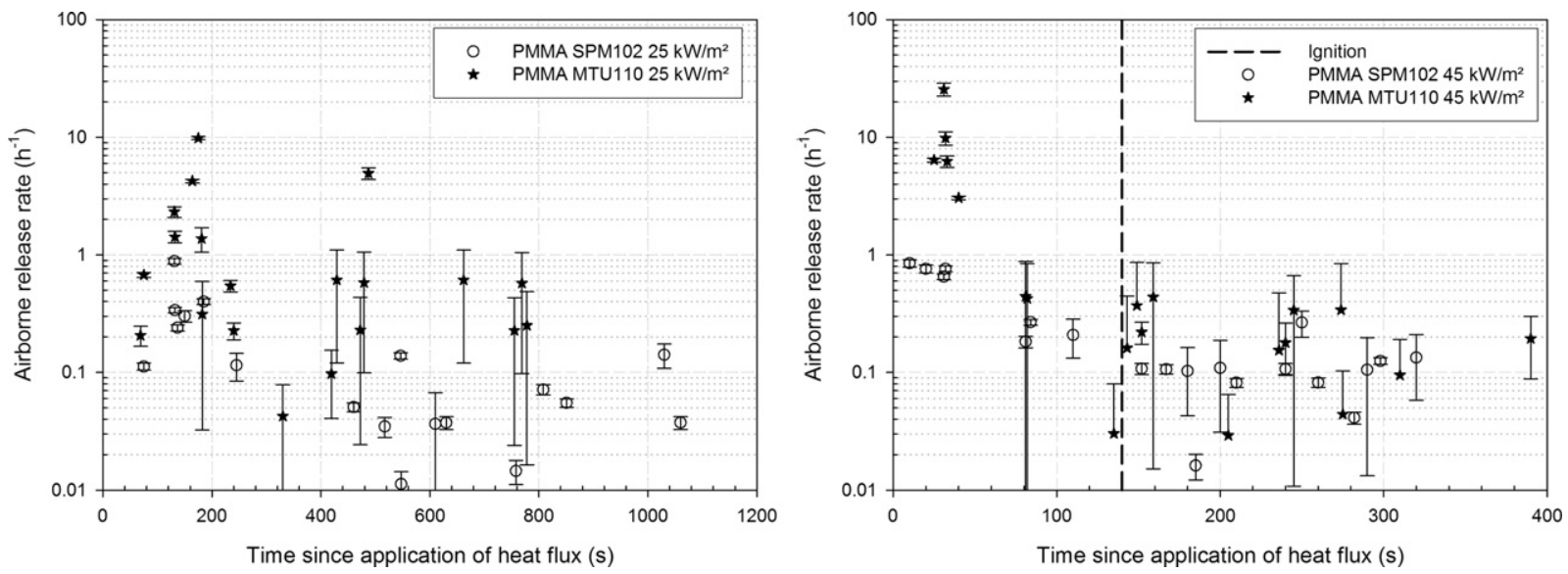

Fig. 7. $\mathrm{Al}_{2} \mathrm{O}_{3}$ release rate (\% per hour) as a function of time since application of heat flux for PMMA.
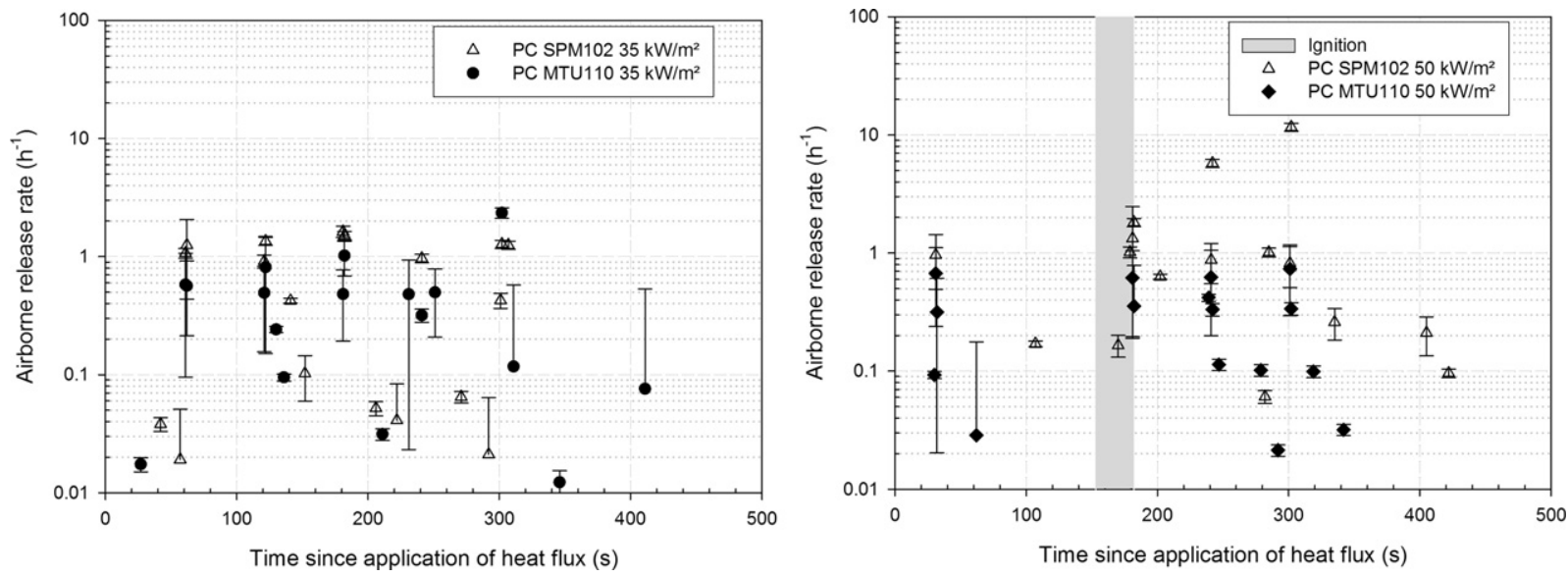

Fig. 8. $\mathrm{Al}_{2} \mathrm{O}_{3}$ release rate (\% per hour) as a function of time since application of heat flux for PC.

clearly highly dependent on heat flux and contaminant particle size, whereas the duration is only dependent on heat flux. Considering the results given in the PhD thesis of Fernandez [10], we present in Fig. 6 the correlation between the duration of the peak release $\left(\mathrm{DT}_{\text {peak }}\right)$ and the heat flux applied to PMMA contaminated with a deposition of $1 \mathrm{mg} / \mathrm{cm}^{2}$. We also propose in this figure an empirical fitting of these results, similar to the one observed between PMMA ignition time and heat flux [21], with $a=3.5 \times 10^{-3} \mathrm{~m}^{2} / \mathrm{kW} \mathrm{s}^{1 / 2}$ and $b=9.7 \times 10^{-3} \mathrm{~s}^{-1 / 2}$.

In the same manner, the evolution of the aerosol release rate (ARR) as a function of time after application of heat flux is presented in Fig. 7 for PMMA. In agreement with visual observations previously described, the ARR slightly increases just after the beginning of the test and, after this peak release period, does not denote a specific trend of evolution. For non-flaming experiments $\left(25 \mathrm{~kW} / \mathrm{m}^{2}\right)$, the ARRs are similar at the beginning of the test for both MTU110 and SPM102, but after $300 \mathrm{~s}$ the ARRs of SPM102 are significantly lower than those measured for MTU110. For flaming experiments $\left(45 \mathrm{~kW} / \mathrm{m}^{2}\right)$, the ARRs appear to be higher for MTU110 during the first $80 \mathrm{~s}$ prior to ignition (mainly during the peak release period) and are similar during combustion.

In contrast with PMMA, no peak release was identified for PC and no specific trend was noticed during the test for each heat flux (see Fig. 8) and data scatter over two orders of magnitude denoting a non-constant airborne release for this fuel. Beyond this scatter, one could mention that the intumescing behaviour of PC is not a reproducible phenomenon and represents a significant experimental limitation and source of data scattering. Furthermore, the evolution of airborne release as a function of time after application of heat flux is not significantly affected by the size of the contaminant particles.

Fig. 9 presents the evolution of the ARR as a function of mass loss rate for PMMA (left) and PC (right). For PMMA, no specific trend of ARR could be observed as a function of mass loss rate. This result is not in agreement with previous results [12] for vertically oriented samples contaminated with $\mathrm{CeO}_{2}$ particles, since these authors identified a significant increase in ARR as mass loss rate increases. On the other hand, no specific trend has been reported for PC, and the ARR appears to be independent of the mass loss rate of the polymer.

\subsection{Particle resuspension fractions}

One of the most useful parameters for describing the release of aerosols is the airborne release fraction ARF. This parameter is determined using the aerosol mass released during every test according to the mass of particles deposited. Mean values of ARF for each fuel were computed (including losses correction according to Section 2.2) as a function of heat flux and size distribution. The results are presented in Table 4 . Considering the mean values presented in Table 4, Fig. 10 shows the ARF obtained respectively for PMMA and PC as a function of heat flux.

In agreement with previous results $[7,10]$, heat flux does not appear to be a significant parameter and only slight discrepancies (which are not significant according to experimental uncertainties) on ARF could be observed between flaming and non-flaming 

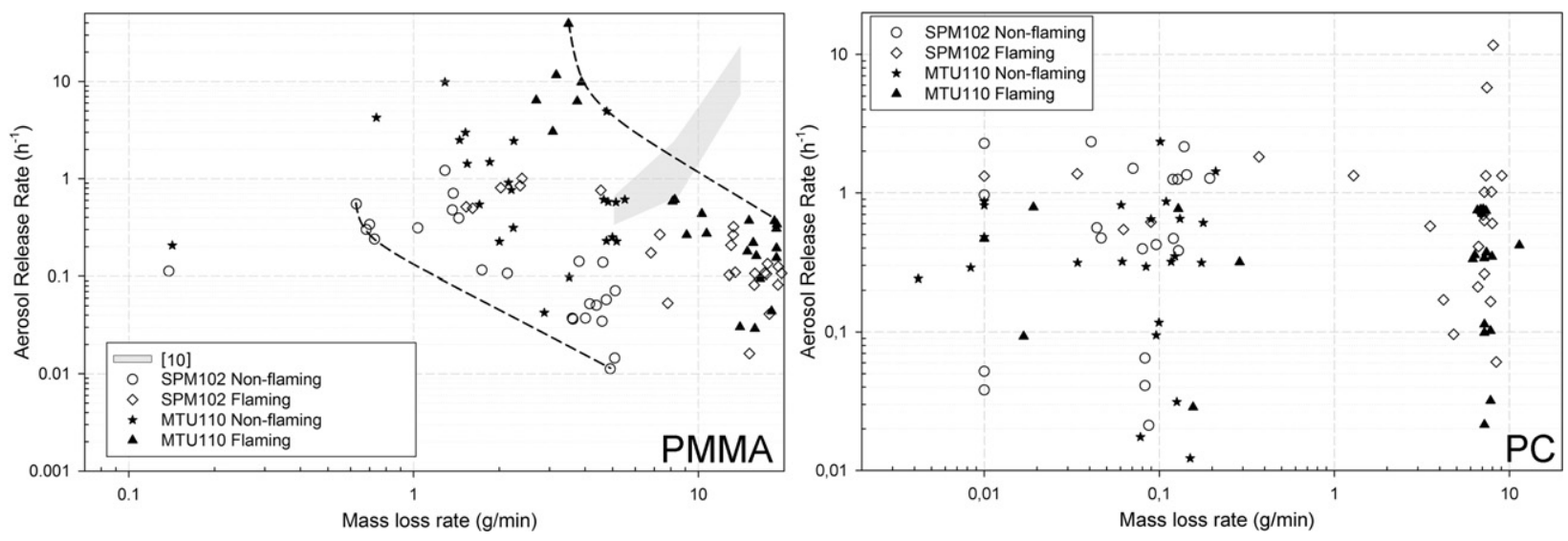

Fig. 9. $\mathrm{Al}_{2} \mathrm{O}_{3}$ release rate (\% per hour) as a function of mass loss rate for PMMA (left) and PC (right).

Table 4

Airborne release fractions obtained for aluminium oxide particles on PMMA and PC (standard deviation in brackets computed from values obtained during 3 similar experiments, $95 \%$ of confidence with $k=2$ ).

\begin{tabular}{lllr}
\hline Fuel & Contaminant & Flux $\left(\mathrm{kW} / \mathrm{m}^{2}\right)$ & \multicolumn{1}{c}{ ARF $(\%)$} \\
\hline PMMA & SPM102 & 25 & $2.1(0.6)$ \\
& & 45 & $2.7(0.1)$ \\
& MTU110 & 25 & $11.4(4.9)$ \\
PC & 45 & $12.2(6.2)$ \\
& SPM102 & 35 & $6.8(3.9)$ \\
& & 50 & $5.8(2.6)$ \\
& MTU110 & 35 & $3.9(2.8)$ \\
& & 50 & $3.2(0.8)$ \\
\hline
\end{tabular}

conditions. However, it should be pointed out that few results are available in the literature regarding the effect of heat flux on ARF. Finally, Fig. 10 demonstrates that ARF reported for flaming or nonflaming conditions, for the two diameters studied and for the two polymers, are not statistically different.

On the other hand, Fig. 11 presents the evolution of ARF as a function of physical particle diameter. The experimental results presented in Fig. 11 only concern horizontally oriented samples and are derived from both the present study and previous studies $[7,12,13]$. According to this figure, it is obvious that the physical diameter of the contaminant particles could be considered as a significant parameter but with varying impact depending on the type of polymer.

For PC, our results show a slight increase in the ARF as the physical diameter increases. Nevertheless, we were not able to identify

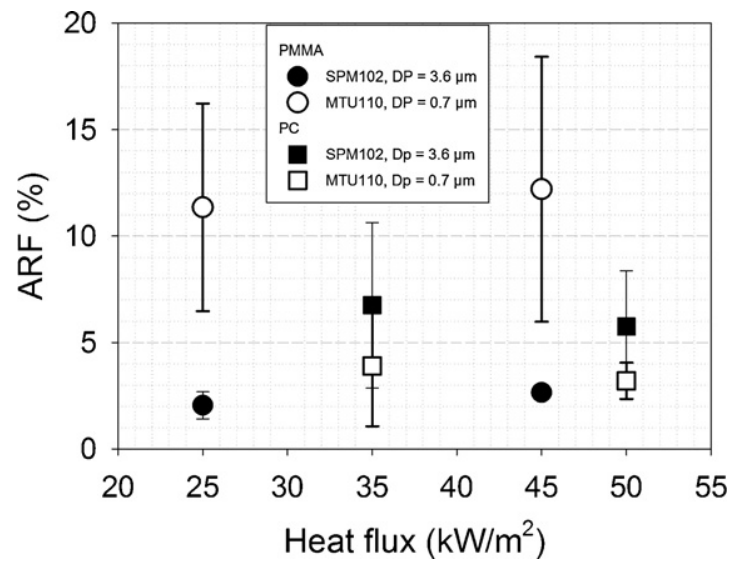

Fig. 10. ARF as a function of heat flux. other results from the literature with the same fuel and further investigations are needed on the effect of particle diameter on ARF associated with polycarbonate.

On the other hand, PMMA has been studied by several authors $[7,12,13]$ and under different conditions allowing us to identify a significant decrease in ARF as a function of particle diameter.

\section{Discussions}

The main discrepancies between PMMA and PC can be summarized in the form of release kinetics. For PMMA, a peak release rate could be identified while for PC the release rate is not significantly higher at the beginning of thermal degradation. This discrepancy is mainly due to bubbles formed during depolymerisation of PMMA. In this situation, and for a temperature ranging from $180^{\circ} \mathrm{C}$ to $210^{\circ} \mathrm{C}$, the energy generated due to bubble bursting at the surface of the polymer is enough to counteract the adhesion forces and thereby to release particles in the gas phase. Therefore, the evolution of the duration of the peak as a function of heat flux (see Fig. 6) could be explained by the time required for the PMMA to reach the upper critical temperature of $210^{\circ} \mathrm{C}[8,9]$, for which the bursting pressure of bubbles formed is too low to extract particles from the PMMA surface. Fig. 6 also presents a comparison of the proposed correlations for the duration of the peak release and the time required to reach a specific PMMA surface temperature [25]. In the case considered here, fairly good agreement is obtained between our results and the time required to reach a

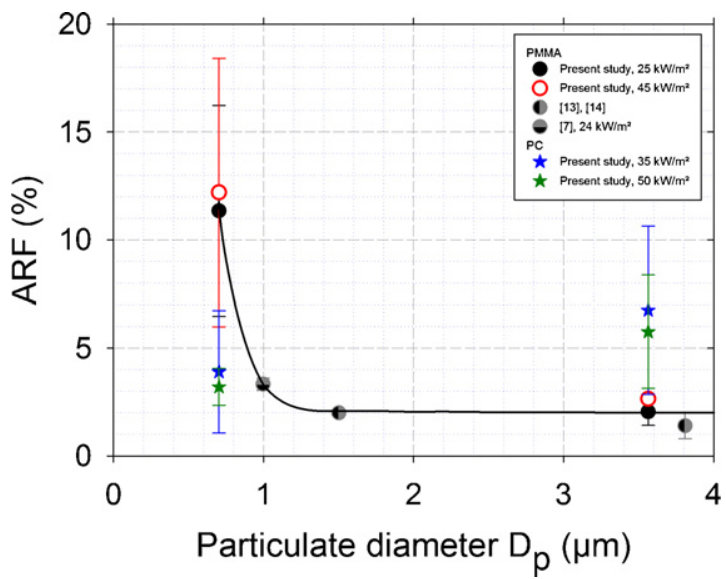

Fig. 11. Evolution of $A R F$ as a function of physical diameter for horizontal PMMA and $\mathrm{PC}$. 
temperature of $275^{\circ} \mathrm{C}$, which is slightly lower than the ignition temperature reported for PMMA on a cone calorimeter [21] but in good agreement with the temperature range $\left(250-275^{\circ} \mathrm{C}\right)$ corresponding to the first step of mass loss of the polymer determined by thermogravimetric analysis (ATG) [25]. Nevertheless, it must be noted that, according to the results presented here, the PMMA surface temperature corresponding to the peak release rate is significantly higher than the critical temperature of $210^{\circ} \mathrm{C}$ reported by previous authors $[8,9]$. To our knowledge, the present quantification of time appearance and duration of this phenomenon has never before been published and despite its empirical character, this fitting makes it possible to easily predict the duration of this peak release.

On the other hand, the uncertainties and scattering of results associated with the ARR measurements obtained during each experiment make it difficult to draw any conclusions on the evolution of ARR as a function of time or, as reported by [12], as a function of mass loss rate. Nevertheless, it should be noted that in the present case (and in contrast to [12]), the samples are horizontally oriented and, consequently, the release of particles due to convective fluxes and fire plume is less pronounced than for a vertical orientation. Direct measurement of ARR by Laser Induced Breakdown Spectroscopy [26] will be implemented on our test bench to measure its evolution in near real time and to accurately describe the aerosol release kinetics during the first moments of the experiment.

Regarding the ARF, our experimental results demonstrate that, for our conditions, the heat flux is not a significant parameter. Nevertheless, this conclusion is supported only by two fluxes for each polymer and further investigations are needed to confirm the low dependency of ARF as a function of heat flux. One interesting point of investigation will be to determine a potential critical heat flux (in contrast with the thermal critical heat flux of $11 \mathrm{~kW} / \mathrm{m}^{2}$ and $15 \mathrm{~kW} / \mathrm{m}^{2}$ respectively for PMMA and PC [27]) corresponding to significant airborne release.

The last point of discussion deals with Fig. 11 and evolution of ARF as a function of geometric particle diameter. Considering the purely aeraulic entrainment of micronic particles, several authors have pointed out that ARF due to air flow increases with increasing physical diameter $[16,17]$. According to these authors, this evolution is explained by drag/lift and balancing adhesive forces (Van der Waals, capillarity, electrostatic and gravity). Assuming only air flow stress, it is obvious that a particle with a physical diameter of $10 \mu \mathrm{m}$ is more easily released than a $1 \mu \mathrm{m}$ one. Nevertheless, our experimental results do not support this evidence and other phenomena could be suspected for counteracting this aeraulic entrainment, such as settling inside melted polymers, bubble bursting, surface tension, etc. Beyond these remarks, another point of discussion remains regarding the particle size distribution of the released aerosol. In the present work we have assumed the size distribution of the airborne released fraction to be similar to the deposited one. Furthermore, in the case considered here, the particles deposited on the polymer surface show a broad size distribution and the evolution of ARF as a function of physical diameter must therefore be interpreted with caution. Nevertheless, this point needs further investigation regarding complex phenomena at particle/polymer interface and some technical improvements for depositing particles at the polymer surface with a narrow size distribution and measuring size distribution of the resuspended particles. As an example, future research will be conducted for particles with physical diameters in the range $0.1-1 \mu \mathrm{m}$ and beyond $10 \mu \mathrm{m}$. An experimental description of the bubbling phase inside melted polymer is currently in progress and will be used to validate a theoretical model recently developed [28] and to quantify the effect of bubble bursting on the release of airborne particles at the burning polymer interface.

\section{Conclusions}

The results presented here show that the release of micronic particles deposited on PMMA mainly occurred during the first instants of pyrolysis and that a peak release was observed, in agreement with previous authors. One of the main contributions of this study remains the relationship between the duration of this peak and the heat flux applied to PMMA samples. Despite this correlation, the heat flux does not appear to influence the airborne release fraction and the results obtained are in agreement for non-flaming and flaming conditions. At the same time, ARF could be linked to the characteristic size of the contaminant particles. Our results agree well with previous results and we can conclude that the release of particles deposited on PMMA samples is a threshold phenomenon.

In contrast to PMMA, we were not able to identify a peak release for PC and the aerosol release rate did not evolve as a function of time or heat flux. In the same way, the contaminant particle size is a significant parameter and ARF tends to increase as the physical diameter of the contaminant particles increases. By comparing this evolution with that obtained for PMMA, the ARF obtained for PC and for particles with diameter smaller than $1 \mu \mathrm{m}$ is lower than for PMMA while it is higher for $D_{\mathrm{p}}$ larger than $1 \mu \mathrm{m}$.

Beyond the discrepancies observed between PMMA and PC, the key issue is the description of particle behaviour located at the surface of thermally degraded polymers. It is well known that PMMA and PC exhibit significantly different fire behaviours, on one hand PMMA forms bubbles during its thermal degradation whereas the intumescence of PC tends to increase its internal porosity and volume during thermal degradation. Further investigations are currently in progress to link the theoretical description of thermal degradation of polymers with the physical and chemical behaviour of particles at particle/polymer interface. The observation of released particles will be also performed by electronic microscopy in order to describe potential interactions between contaminant particles and thermally degraded PMMA and PC.

\section{References}

[1] Nuclear Energy Agency, Fire project report: collection and analysis of fire events (2002-2008)-First application and expected further developments, NEA/CSNI/R (2009) 6.

[2] Y.S. Cheng, R.A. Guilmette, Y. Zhou, J. Gao, T. LaBone, J.J. Whicker, M.D. Hoover, Characterization of plutonium aerosol collected during an accident, Health Phys. 87 (6) (2004) 596-605.

[3] K. Vishwa Prasad, A.Y. Balbudhe, G.K. Srivastava, R.M. Tripathi, V.D. Puranik, Aerosol size distribution in a uranium processing and fuel fabrication facility, Radiat. Prot. Dosimetry 140 (2010) 357-361.

[4] C. Motzkus, C. Chivas-Joly, E. Guillaume, S. Ducourtieux, L. Saragoza, D. Lesenechal, T. Macé, J.-M. Lopez-Cuesta, C. Longuet, Aerosols emitted by the combustion of polymers containing nanoparticles, J. Nanopart. Res. 14 (3) (2012) 687.

[5] M.R. Nyden, R.H. Harris, Y.S. Kim, R.D. Davis, N.D. Marsh, M. Zammarano. Characterizing particle emissions from burning polymer nanocomposites, Nanotechnology 2010: Advanced Materials, Cnts, Particles, Films And Composites-Technical Proceedings Of The 2010 NSTI Nanotechnology Conference And Expo, NSTI-Nanotech. 1 (2010) 717-719.

[6] J. Mishima, L.C. Schwendiman, The amount and characteristics of plutonium made airborne under thermal stress, in: Fifth Midyear Symposium of the Health Physics Society, Idaho Falls, Idaho, 1970.

[7] M.A. Halverson, M.Y. Ballinger, G.W. Dennis, Combustion aerosols formed during burning of radioactively contaminated materials, Exp. Results (1987) NUREG/CR 4736. PNL-5999.

[8] S. Pickering, A mechanism for the resuspension of particles from burning Plexiglas, J. Aerosol Sci. 17 (1986) 602-607.

[9] S. Pickering, Resuspension of uranium-plutonium oxide particles from burning Plexiglas, J. Aerosol Sci. 18 (1987) 927-930.

[10] Y. Fernandez, Etude expérimentale de l'émission d'aérosols radioactifs lors de la dégradation thermique de matériaux organiques contaminés présents dans les installations nucléaires. (Experimental study on release of radioactive aerosols during the thermal degradation of contaminated organic materials present in nuclear installation). In French. PhD Thesis, Université de Savoie. Rapport CEAR-5663 (1993)

[11] Y. Fernandez, N. Lauvergne, P. Burghoffer, Etude expérimentale, à petite échelle, de l'émission d'aérosols de cerium, césium, cobalt et lanthane pour différentes 
configurations de combustion de plaques de polyméthacrylate de méthyle (Plexiglas) [Experimental study, at small scale, on aerosols emission of ceria, caesium, cobalt and lanthanum for different combustion configurations of polymethyl methacrylate sheets]. Experimental report DPEI/SERAC/LESI/94.13 (1994).

[12] Y. Fernandez, P. Burghoffer, Radioactive aerosols emissions in fires, Aerosol Sci. Tech. 23 (2) (1995) 231-238.

[13] K. Buijs, B. Chavane de Dalmassy, S. Pickering, The dispersion of radioactive aerosols in fire, J. Nucl. Mater. 166 (1989) 199-207.

[14] K. Buijs, B. Chavane de Dalmassy, E. Baumgärtner, Contaminated Smoke: A Simulation of the Heavy Metal Containing Aerosols from Fires in Plutonium Glove Boxes. Part II. Eur 14494 en, European Institute for Transuranium Elements, Karlsruhe, Germany, 1992.

[15] V. Kogan, P.M. Schumacher, Plutonium release fractions from accidental fires, Nucl. Tech. 161 (2008) 190-202.

[16] L. Biasi, A. De Los Reyes, M.W. Reeks, G.F. De Santi, Use a simple model for the interpretation of experimental data on particle resuspension in turbulent flows, J. Aerosol Sci. 32 (2001) 1175-1200.

[17] M.W. Reeks, D. Hall, Kinetic models for particle suspension in turbulent flows: theory and measurement, J. Aerosol Sci. 32 (2001) 1-31.

[18] B.J. Holland, J.N. Hay, The kinetics and mechanisms of the thermal degradation of poly(methyl methacrylate) studied by thermal analysis-Fourier transform infrared spectroscopy, Polymer 42 (2001) 4825-4835.

[19] B.N. Jang, C.A. Wilkie, TGA/FTIR and mass spectral study on the thermal degradation of bisphenol A polycarbonate, Polym. Degrad. Stabil. 86 (2004) 419-430.
[20] S.L. Von Deer Weiden, F. Drewnick, S. Borrmann, Particle loss calculator-a new software tool for the assessment of the performance of aerosol inlet systems, Atmos. Meas. Tech. 2 (2009) 479-494.

[21] T.H. Tsai, M.J. Lin, I.Y. Shih, R. Jih, S.C. Wong, Experimental and numerical study of autoignition and pilot ignition of PMMA plates in a cone calorimeter, Combust. Flame 124 (2001) 466-480.

[22] ISO 5660-1:2002(E), Reaction to fire tests-heat release, smoke production and mass loss rate-Part 1: heat release rate (cone calorimeter method) (2002).

[23] ISO 5660-2:2002(E), Reaction to fire tests-heat release, smoke production and mass loss rate-Part 2: smoke production rate (dynamic measurement) (2002).

[24] ISO 5660-3:2003(E), Reaction to fire tests-heat release, smoke production and mass loss rate-Part 3: guidance on measurement (2003).

[25] A. Laachachi, M. Cochez, M. Ferriol, J.-M. Lopez-Cuesta, E. Leroy, Influence of $\mathrm{TiO}_{2}$ and $\mathrm{Fe}_{2} \mathrm{O}_{3}$ fillers on the thermal properties of poly(methyl methacrylate) (PMMA), Mater. Lett. 59 (2005) 36-39.

[26] G. Gallou, J.B. Sirven, C. Dutouquet, O. Le Bihan, E. Frejafon, Aerosols analysis by LIBS for monitoring of air pollution by industrial sources, Aerosol Sci. Technol. 45 (2011) 918-926.

[27] A. Tewarson, Generation of heat and chemical compounds in fire, in: SFPE Handbook of Fire Protection Engineering, 3rd ed., National Fire Protection Association, Quincy, Massachusetts, 2002.

[28] K.M. Butler, A numerical model for combustion of bubbling thermoplastic materials in microgravity, NISTIR 6894 (2002). 